$\begin{gathered}\text { Revista do Departamento de Geografia } \\ \text { Universidade de São Paulo } \\ \text { www.revistas.usp.br/rdg }\end{gathered}$
Volume Especial - XVII SBGFA / I CNGF (2017)

\title{
Inventário dos Escorregamentos da Bacia do Rio Gurutuba, Vale do Ribeira (SP)
}

\section{Landslides Inventory of Gurutuba River Basin, Ribeira Valley (SP)}

Camila Bertaglia Carou

Universidade de São Paulo carou@usp.br

Bianca Carvalho Vieira

Universidade de São Paulo biancacv@usp.br

Tiago D. Martins

Universidade Federal de Pernambuco martins.td@gmail.com

Marcelo Fischer Gramani
Instituto de Pesquisas Tecnológicas de São Paulo
mgramani@ipt.br

Recebido (Received): 18/03/2017

DOI: $10.11606 /$ rdg.v0ispe. 133377

Aceito (Accepted): 12/06/2017

Resumo: A cidade de Itaóca, Vale do Ribeira, foi atingida por três grandes processos relacionados a um volume pluviométrico extremo no mês de janeiro de 2014. A precipitação, concentrada nas cabeceiras de três bacias, rio Palmital, Guarda-Mão e Gurutuba, deflagrou um grande número de escorregamentos rasos, corrida de detritos na bacia do Guarda-Mão e inundação na área urbana. Assim, o presente trabalho teve como objetivo avaliar a frequência e algumas características dos escorregamentos deflagrados na bacia do Gurutuba. Os resultados mostraram que a maior concentração de cicatrizes ocorreu nos terços médio e inferior da bacia, sendo que a maior parte das cicatrizes possui dimensões de até $300 \mathrm{~m}^{2}$, com o predomínio da classe entre $100 \mathrm{~m}^{2}$ $150 \mathrm{~m}^{2}$. Estes dados poderão contribuir para trabalhos posteriores como uso de ferramentas estatísticas ou modelos matemáticos de previsão de escorregamentos

\begin{abstract}
The Itaóca municipality, located in the Ribeira Valley, was affected by three major processes related to an extreme rainfall in January 2014. The rainfall, concentrated in the headwaters of the three basins, Palmital River, Guarda-Mão and Gurutuba, triggered a significant number of shallow landslides, debris flows in the Guarda-Mão Basin and flooding in the urban area. Thus, the present paper had as objective to evaluate the frequency and some characteristics of the shallow landslides in the Gurutuba basin. The results showed that the greatest concentration of scars occurred in the middle and lower sectors of the basin, and most scars have dimensions of up to $300 \mathrm{~m}^{2}$, with ruling class between $100 m^{2}-150 m^{2}$. These data may contribute to future works such as the use of statistical tools or mathematical models for predicting landslides.
\end{abstract}

Palavras-chave: Itaóca; Movimentos de Massa; Cicatrizes; Índice de Frequência.
Keywords: Itaóca, Mass Movements, Scars, Frequency Index. 


\section{INTRODUÇÃO}

Entre os dias 13 e 14 de janeiro de 2014, a cidade de Itaóca, sul do Estado de São Paulo, foi atingida por uma forte precipitação pluviométrica, registrando cerca de $200 \mathrm{~mm}$ em 2 horas (GRAMANI E ARDUIN, 2015) que se concentraram sobretudo nas cabeceiras de três bacias hidrográficas, a do Rio Palmital, GuardaMão e Gurutuba. Tal evento pluviométrico deflagrou diversos escorregamentos, gerou inundação e uma expressiva corrida de detritos na bacia do córrego Guarda-Mão. O acidente provocou 25 óbitos, 3 desaparecidos, 203 pessoas desabrigadas ou desalojadas (BROLLO et al., 2015) e 100 casas afetadas (BRASIL, 2014).

Tendo em vista que os movimentos de massa variam conforme o material remobilizado, a velocidade e mecanismo do movimento, modo de deformação, geometria e conteúdo de água (SELBY, 1993), com base na classificação de Varnes (1978), a tipologia predominante no evento foi de escorregamentos translacionais rasos, caracterizados pelo rápido deslocamento de solo em uma superfície de ruptura plana. Assim, considerando os processos geomorfológicos predominantes na área, bem como as condições de suscetibilidade e riscos envolvidos nas suas dinâmicas, é importante a avaliação da distribuição destes processos na paisagem.

Os mapas de inventário fornecem informações importantes sobre a distribuição e algumas características das cicatrizes (ex. área e forma), além de serem utilizados em análises estatísticas, métodos heurísticos (CARRARA et al., 1995; VAN WESTEN 2004), análise dos seus fatores condicionantes (AUGUSTO FILHO E MAGALHÃES, 2004; AGILI et al. 2004; AVANZI et al., 2004) e para validação de modelos matemáticos de previsão (WU E SIDLE 1995; DIETRICH et al.,1998; SALCIARINI et al., 2006). Desta forma, o presente trabalho teve como objetivo realizar um inventário dos escorregamentos rasos na bacia do rio Gurutuba, uma das mais afetadas por este evento (Figura 1), avaliando suas formas, setores e áreas de ocorrência predominantes.

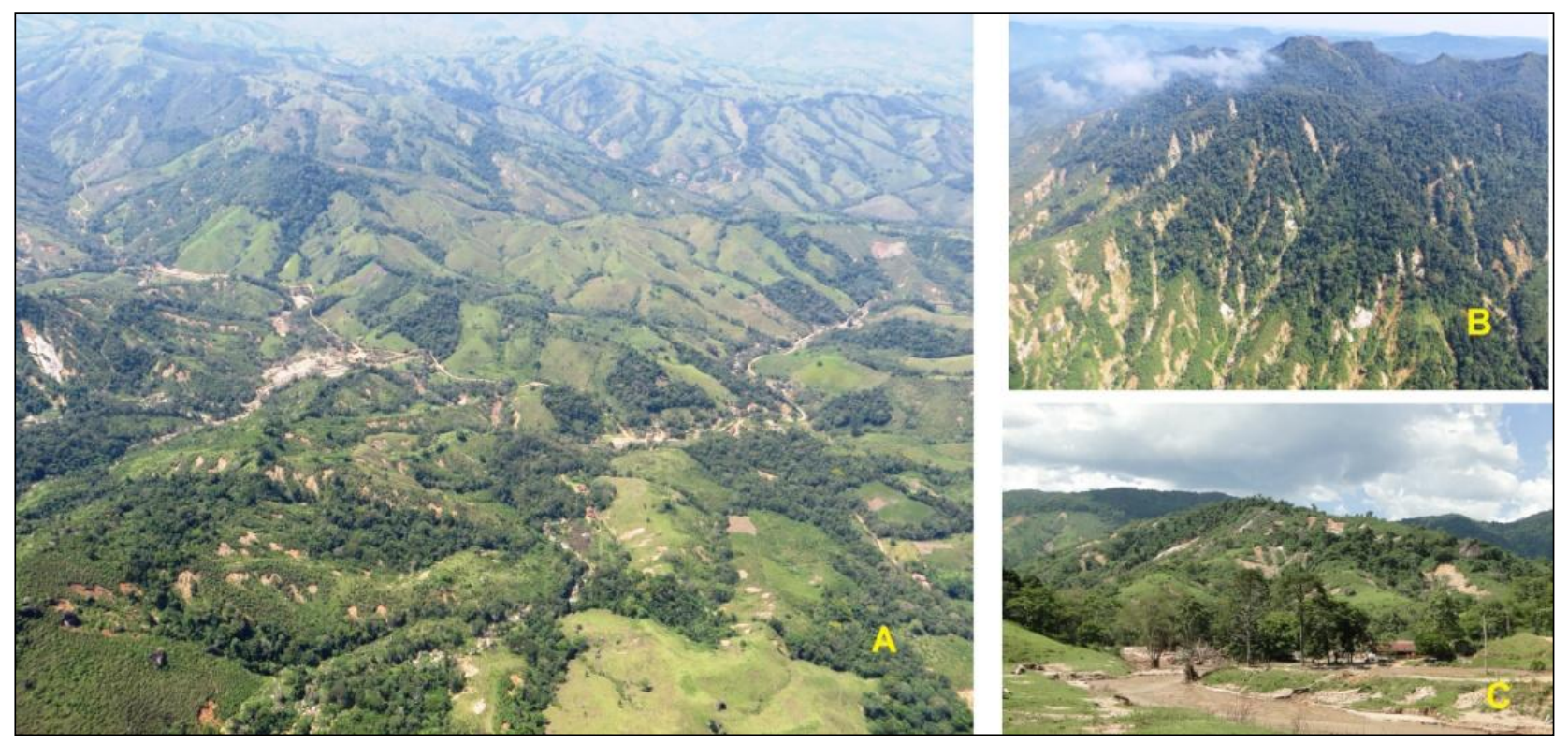

Figura 1: A) Vista geral da bacia do Rio Gurutuba; B) Foto aérea das cicatrizes dos escorregamentos ocorridos no evento de 2014; C) Vista terrestre das cicatrizes.

\section{Área de Estudo - Bacia do Rio Gurutuba}

Localizada no contexto do Vale do Ribeira, a bacia do rio Gurutuba (Figura 2), é uma das principais bacias que drenam para a cidade de Itaóca. Sua confluência é dada com o rio Palmital, e se insere no contexto da Unidade de Gerenciamento de Recursos Hídricos (UGRHI) 11 - Ribeira de Iguape. A bacia possui $24,4 \%$ da área com encostas que variam entre $25^{\circ}$ e $30^{\circ}$, uma amplitude altimétrica de cerca de $700 \mathrm{~m}$. 


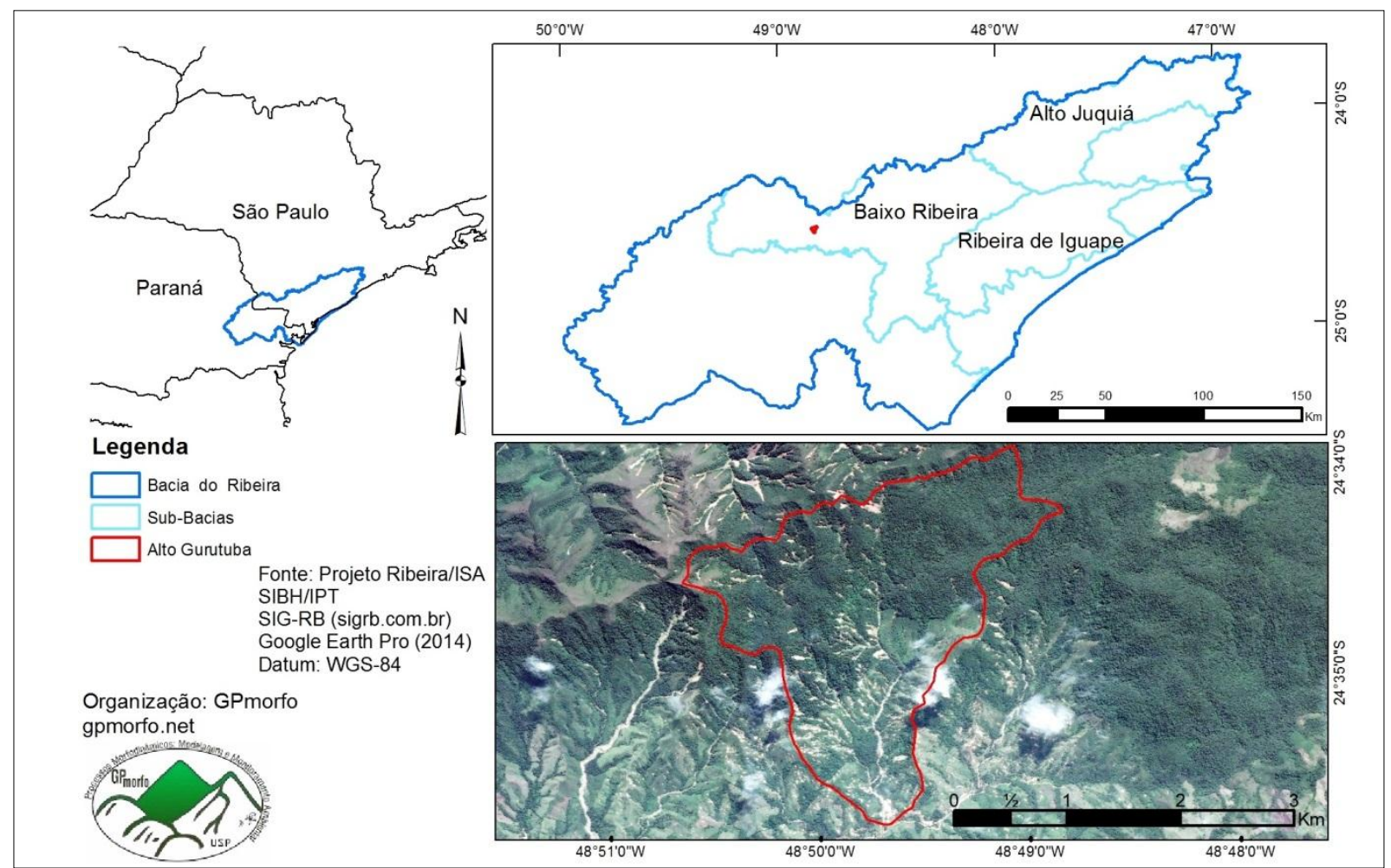

Figura 2: Localização da área de estudo no contexto da bacia do rio Ribeira de Iguape.

A área de estudo está inserida em um contexto geológico regional integrado ao Supergrupo Açungui, Grupo Lajeado, de terrenos pré-cambrianos do Cinturão Ribeira. Neste contexto encontra-se o Batólito Granitóide Itaóca, localizado próximo às Zonas de Cisalhamento Ribeira (ZCR) e Figueira (ZCF), o qual embasa a bacia do rio Gurutuba. Tal embasamento se constitui de granitóides calcioalcalinos monzoníticos e por metassedimentos encaixantes do Subgrupo Lageado (FALEIROS et al., 2012; MELLO E BETTENCOURT, 1998).

Segundo Ross e Moroz (1997), a área encontra-se inserida no contexto do Cinturão Orogênico do Atlântico, na unidade do Planalto do Ribeira/Turvo, onde as feições predominantes são morros altos com topos aguçados e topos convexos, com uma variação do entalhamento dos vales entre $20 \mathrm{~m}$ e $80 \mathrm{~m}$ e uma variação de dimensão interfluvial entre $750 \mathrm{~m} \mathrm{e} 1.750 \mathrm{~m}$. Esta unidade possui formas muito dissecadas, apresentando, desta forma, vales entalhados e alta densidade de drenagem (ROSS E MOROZ op. cit.).

De acordo com Brollo et al. (2015), a pedogênese local é incipiente, observando-se então um espesso manto de alteração argilo-síltico-arenoso nos setores côncavos das vertentes, tendo alta suscetibilidade a erosão e escorregamentos. Assim, de modo geral, a área é caracterizada por grande amplitude altimétrica, recobrimento de granito intemperizado - onde não há grande desenvolvimento horizontal pedológico - e cobertura vegetal nativa (Mata Atlântica).

\section{MATERIAIS E MÉTODOS}

O mapa de cicatrizes dos escorregamentos foi elaborado a partir da interpretação de imagem do Google Earth Pro georeferenciada e datada de 10/08/2014. Este mapeamento foi realizado com base em uma análise visual dessas feições, com ajuda da sobreposição de curvas de nível oriundas de cartas topográficas em escala 1:10.000 (Folha Rio das Pedras e Palmital, do Instituto Geográfico e Cartográfico do Estado de São Paulo), utilizando-se a ausência de vegetação e a posição da encosta como principais critérios para a identificação das cicatrizes (Figura 3). Esse último critério foi definido a partir de trabalhos já realizados na Serra do Mar no estado de São Paulo, os quais mostram que as rupturas dos escorregamentos translacionais rasos ocorrem no terço superior da cicatriz. Nos terços médio e inferior ocorrem sobretudo o transporte e a deposição do material, sendo, portanto, áreas excluídas do mapeamento. 


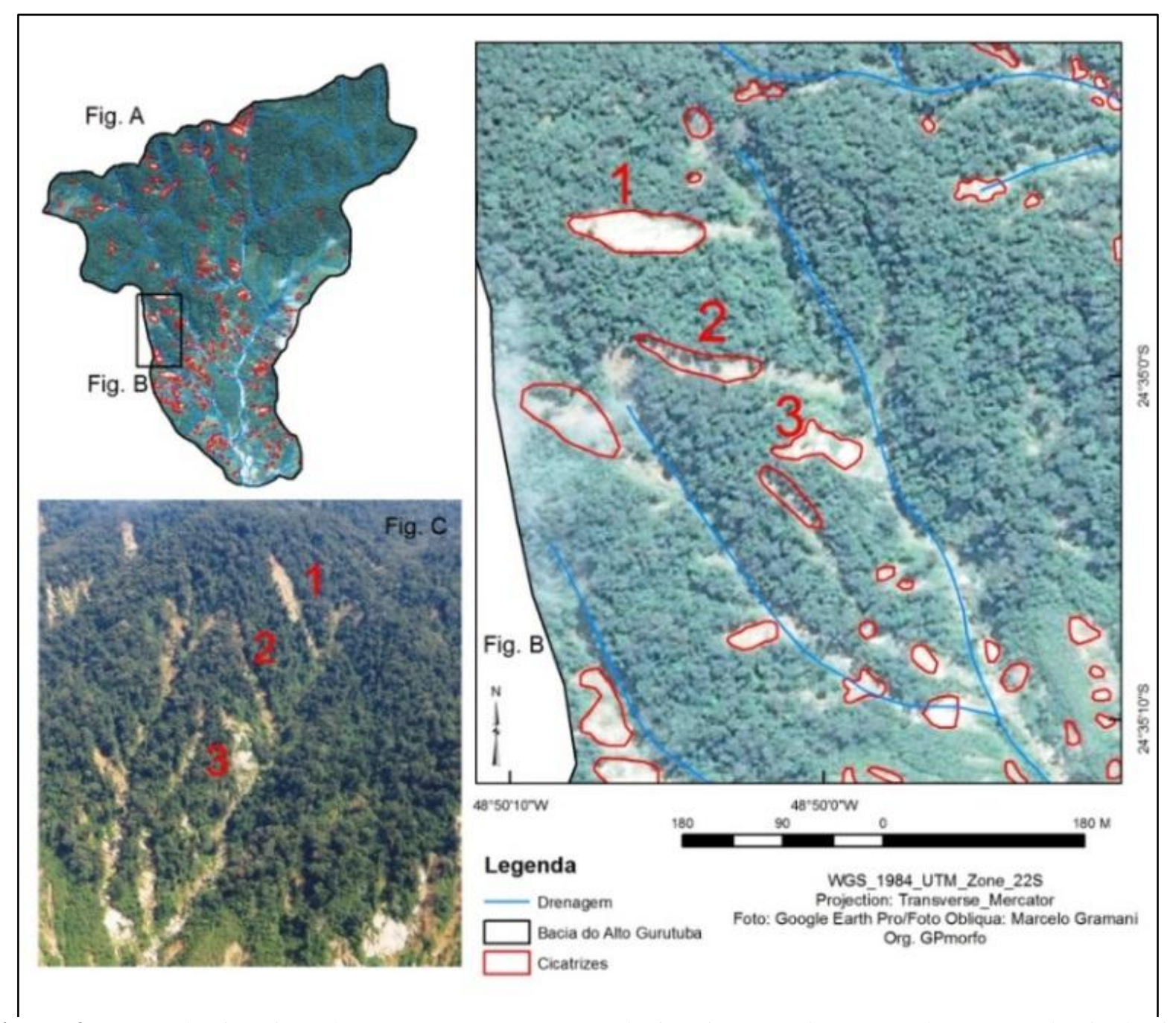

Figura 3: Mapa de cicatrizes dos escorregamentos translacionais rasos do evento de 2014 na bacia do rio Gurutuba (A), indicando os polígonos em vermelho com apenas o terço superior (B). (C) foto oblíqua das cicatrizes dos escorregamentos com destaques para as cicatrizes 1,2 e 3.

\section{RESULTADOS E DISCUSSÕES}

A bacia de estudo apresenta uma área de $4,5 \mathrm{~km}^{2}$, sendo que cerca de $3,27 \%$ da área foi afetada por um único evento, com 336 cicatrizes. Estas se concentraram à margem esquerda do rio principal tendo baixa incidência na porção noroeste da bacia e nenhum registro na porção norte (Figura 4). Em relação à posição nas encostas, destaca-se que as mesmas ocorreram próximas a canais intermitentes ou perenes, tendo sua zona de passagem/arraste direcionadas aos mesmos. Tal comportamento demonstra uma possivel relação entre as rupturas com as áreas de maior acúmulo de água dessas encostas.

Quanto à forma, pode-se dividir as cicatrizes em duas categorias para este trabalho: alongadas, que possuem maior dimensão, e predominam na bacia, e arredondadas, que apresentam menor dimensão, e também estão em número considerável. A maior concentração de cicatrizes ocorre em média e baixa bacia, com predominio das formas mais arredondadas. Já no terço superior, alta bacia, a ocorrência de cicatrizes é reduzida, apresentando formas mais alongadas como destaque (Figura 4).

O evento gerou cicatrizes de grandes proporções, sendo a maior com uma área de $5548 \mathrm{~m}^{2}$ e a menor com apenas $13 \mathrm{~m}^{2}$. Contudo, a maior parte das cicatrizes possui áreas em torno de 50-300 $\mathrm{m}^{2}$ (Figura 5A). Os resultados mostraram a grande representatividade de cicatrizes com área de até $300 \mathrm{~m}^{2}$ (Figura 5C) e a ocorrência de 24 grandes cicatrizes acima de $900 \mathrm{~m}^{2}$ (Figura 5B). Sendo assim, a média das áreas sofreu interferência de valores altos, e discrepantes, mas mesmo assim mostrou a tendência de proximidade à classe predominante com uma média de $429,5 \mathrm{~m}^{2}$ e mediana $177 \mathrm{~m}^{2}$. 


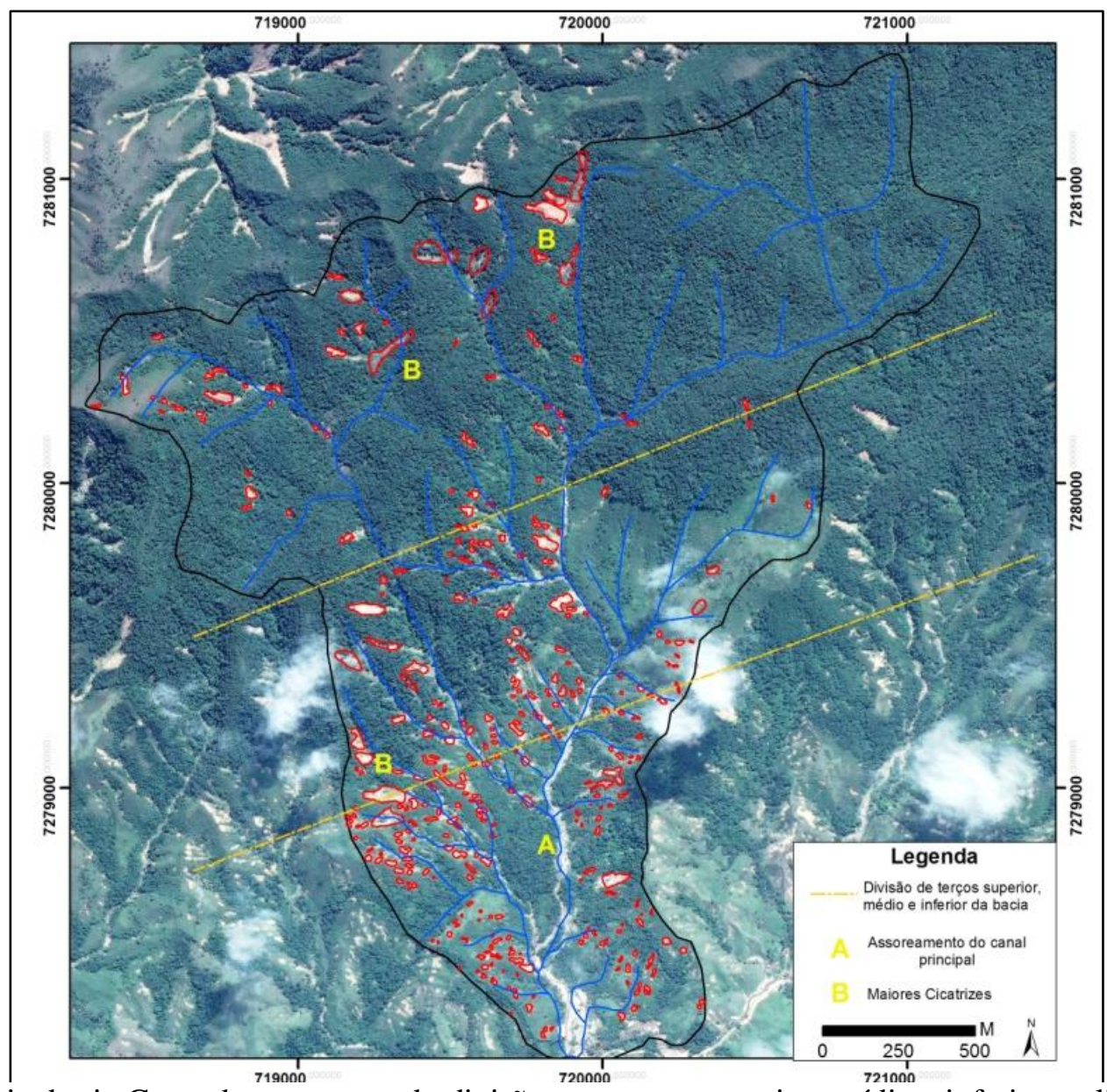

Figura 4: Bacia do rio Gurutuba apresentando divisão entre terço superior, médio e inferior realizada a partir de análise visual da diferença hipsométrica, com base no MDT, mostrando (A) assoreamento do canal principal e (B) setores com as maiores cicatrizes do evento

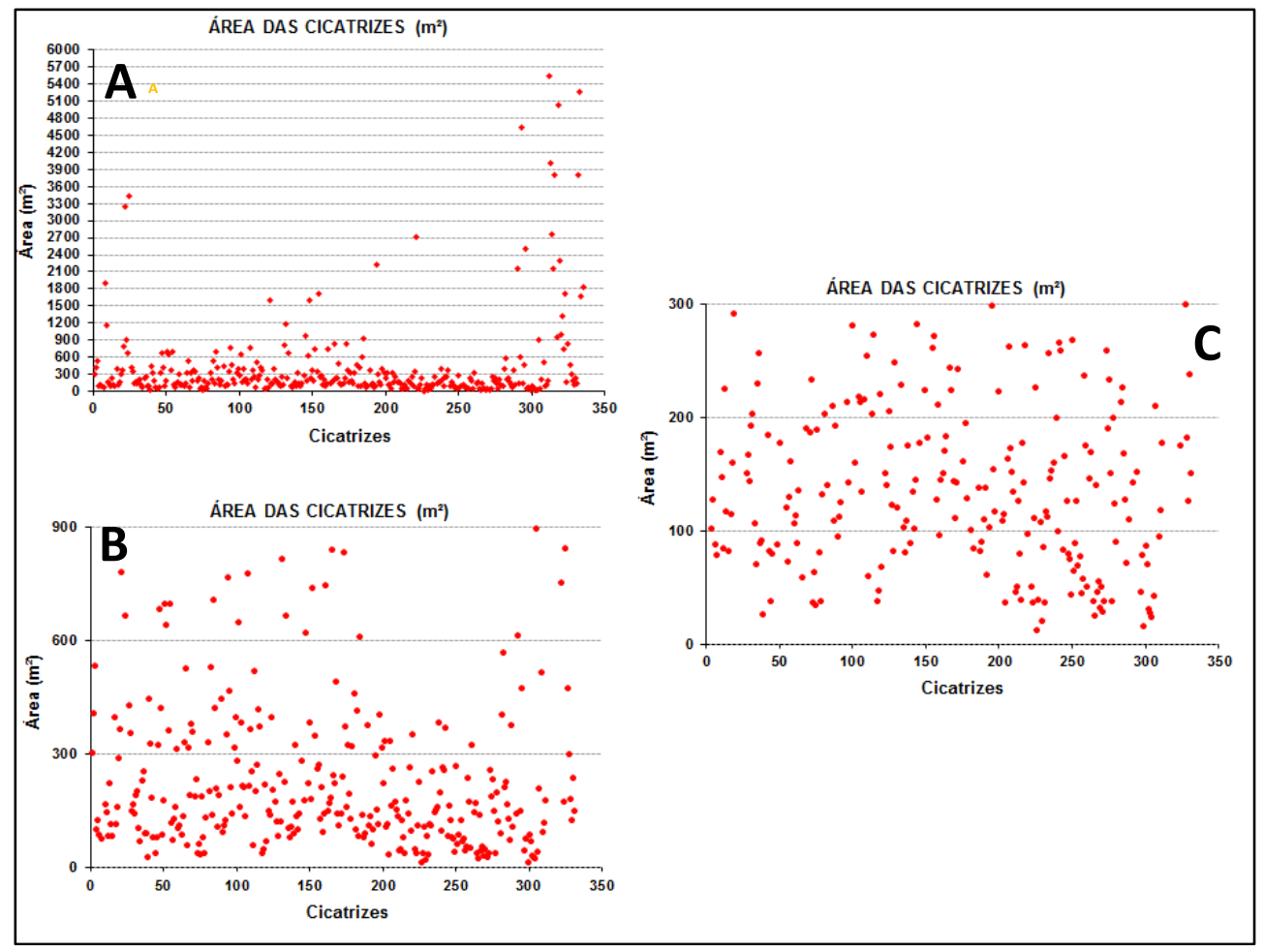

Figura 5: Distribuição de cicatrizes dos escorregamentos mapeados (eixo $\mathrm{x}$ ) em relação à área ocupada por cada uma (eixo y). A) Distribuição de todas as cicatrizes mapeadas; B) Destaque à porção de 0-900 que possuí maior concentração; C) Detalhamento da distribuição das cicatrizes da porção com maior concentração. 
Na Figura 6A pode-se verificar a distribuição geral das áreas das cicatrizes, com destaque para a classe de 100-300 $\mathrm{m}^{2}$, que representa $43 \%$ do total, e para a classe de $1100-1300 \mathrm{~m}^{2}$, que representa o valor mínimo $(0,89 \%)$. Dada esta grande concentração de classes, a Figura 6B destaca as informações contidas nesse intervalo numérico, demonstrando uma maior frequência de escorregamentos com área entre 100-150 $\mathrm{m}^{2}$.

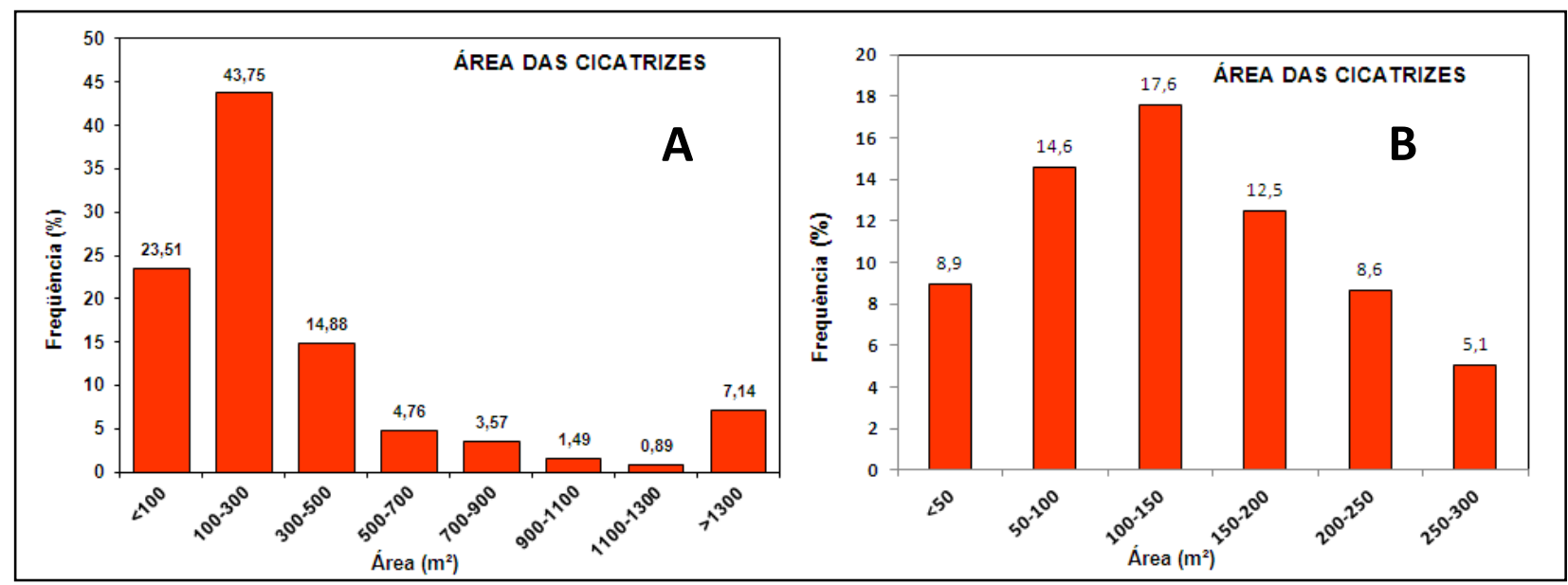

Figura 6: A) Distribuição da área de cicatrizes; B) Detalhamento entre as classes 0-300 m, na qual existe maior concentração de cicatrizes.

A distribuição espacial das cicatrizes e suas dimensões podem estar associadas aos parâmetros morfológicos das vertentes, ou seja, orientação, curvatura, ângulo da encosta e geologia, os quais controlam, por exemplo, a dinâmica da água no solo e interferem diretamente na deflagração de escorregamentos. Ressalta-se que neste trabalho a litologia não pode ser considerada na distribuição dos escorregamentos pois toda a bacia possui o mesmo tipo litológico. Contudo, estruturalmente, Lin et al. (2016) observaram que a frequência dos escorregamentos se apresenta diretamente proporcional à proximidade com os lineamentos, o que ocorre com frequência nas bacias da Serra do Mar, do Vale do Rio Ribeira.

A área e número de cicatrizes, assim como o tamanho da bacia, são similares aqueles encontrados por Vieira (2007) na Serra de Cubatão para o evento de janeiro de 1985. Neste trabalho a maior parte das cicatrizes também possuía até $300 \mathrm{~m}^{2}$, sendo a menor cicatriz com área muito semelhante ao presente trabalho $\left(11 \mathrm{~m}^{2}\right)$ e a área total afetada também ficou em torno de $3 \%$ da área total (Tabela 1).

Tabela 1: Comparação de inventários de trabalhos na Serra do Mar.

\begin{tabular}{|c|c|c|c|c|c|}
\hline Referência & $\begin{array}{c}\text { Área } \\
\left(\mathbf{K m}^{2}\right)\end{array}$ & $\begin{array}{l}\text { Número de } \\
\text { cicatrizes }\end{array}$ & Litologia & $\begin{array}{c}\begin{array}{c}\text { Índice } \\
\text { pluviométrico } \\
\text { (evento) }\end{array} \\
\end{array}$ & Localização \\
\hline \multirow{2}{*}{ Lopes (2006) } & 5,3 & 347 & Migmatitos & $\begin{array}{c}379,4 \mathrm{~mm} / 48 \mathrm{~h} \\
(1985)\end{array}$ & \multirow{2}{*}{$\begin{array}{c}\text { Serra do Mar } \\
\text { Paulista, Cubatão }\end{array}$} \\
\hline & 3,5 & 182 & Migmatitos & $\begin{array}{l}280 \mathrm{~mm} / 24 \mathrm{~h} \\
(1994)\end{array}$ & \\
\hline \multirow{3}{*}{ Nery (2016) } & 37 & 106 & \multirow{3}{*}{$\begin{array}{l}\text { Granitos, gnaisses, } \\
\text { migmatitos e micaxistos }\end{array}$} & \multirow{3}{*}{$\begin{array}{l}420 \mathrm{~mm} / 24 \mathrm{~h} \\
(1985)\end{array}$} & \multirow{3}{*}{$\begin{array}{l}\text { Serra do Mar } \\
\text { Paulista, } \\
\text { Caraguatatuba }\end{array}$} \\
\hline & 19 & 51 & & & \\
\hline & 37 & 75 & & & \\
\hline Vieira (2007) & 3,6 & 356 & $\begin{array}{c}\text { Migmatitos, Granitóides } \\
\text { sintectônicos e Micaxistos }\end{array}$ & 380 mm/48h (1985) & $\begin{array}{c}\text { Serra do Mar } \\
\text { Paulista, Cubatão }\end{array}$ \\
\hline Autores & 4,5 & 336 & $\begin{array}{c}\text { Granito Itaóca (Granitóides } \\
\text { calcioalcalinos } \\
\text { monzoníticos) }\end{array}$ & $\begin{array}{l}200 \mathrm{~mm} / 2 \mathrm{~h} \\
(2014)\end{array}$ & $\begin{array}{c}\text { Serra do Mar } \\
\text { Paulista, Vale do } \\
\text { Ribeira }\end{array}$ \\
\hline Nery (2011) & 2,5 & 216 & Migmatitos e Micaxistos & 380 mm/48h (1985) & $\begin{array}{c}\text { Serra do Mar } \\
\text { Paulista, Cubatão }\end{array}$ \\
\hline $\begin{array}{l}\text { Vieira e Ramos } \\
\text { (2015) }\end{array}$ & 24 & 131 & Gnaisses, metassedimentos & $\begin{array}{l}324,8 \mathrm{~mm} / 48 \mathrm{~h} \\
(1967)\end{array}$ & $\begin{array}{l}\text { Serra do Mar } \\
\text { Paulista, } \\
\text { Caraguatatuba }\end{array}$ \\
\hline
\end{tabular}


O número de cicatrizes de Lopes (2006) para o evento de 1985, em uma das bacias estudadas, também foi muito próximo ao encontrado aqui, sendo uma área total de 5,3 $\mathrm{km}^{2}$ e 337 cicatrizes. Para outra bacia, também na serra de Cubatão, o autor registrou 182 escorregamentos em uma bacia com 3,5 km².

\section{CONCLUSÕES}

A análise do índice de frequência demonstrou, a partir dos dados das áreas das cicatrizes, que tal evento geomorfológico foi de alta magnitude e sua correlação com eventos anteriores na Serra do Mar Paulista. O evento pluviométrico extremo, concentrado nas cabeceiras das três principais bacias hidrográficas da cidade, resultou em três diferentes processos geomorfológicos de grande potencial destrutivo: corrida de detritos, escorregamentos rasos e inundação.

Quanto às características gerais das cicatrizes, percebe-se que as mesmas se concentraram em média e baixa bacia, apresentando, majoritariamente, formas alongadas e dimensões entre $100-150 \mathrm{~m}^{2}$, e com valores discrepantes, como cicatrizes com áreas entre $13 \mathrm{~m}^{2}$ e acima de $900 \mathrm{~m}^{2}$. Tais características podem estar associadas aos parâmetros morfométricos das encostas que poderão ser trabalhados e associados futuramente.

A quantidade de material remobilizado não foi estimada neste trabalho, contudo, a partir dos dados aqui apresentados é possível realizar tal estimativa. Mesmo assim, foi possível perceber, qualitativamente, o grande volume de material remobilizado no processo. Tal dado é corroborado pela observação do terço inferior do canal principal, que apresenta tonalidades muito próximas ao branco e rugosidades associadas a materiais remobilizados nas encostas de grande granulometria, como matacões.

\section{AGRADECIMENTOS}

Os autores agradecem ao Conselho Nacional de Desenvolvimento Científico e Tecnológico - CNPq - pelo financiamento, em andamento, desta pesquisa, ao Programa de Pós-Graduação em Geografia Física da Universidade de São Paulo e ao Instituto de Pesquisas Tecnológicas de São Paulo - IPT. Também agradecem aos revisores do XVII SBGFA/I CNGF.

\section{BIBLIOGRAFIA}

AGILI, F., A. BARTARTOLOMEI, N. CASAGLI, P. CANUITE, L. CATANI, L. ERMINI, P. FARINA, M. KUKAVICIC, M. MIRANNALTI; G. RIGHNI. Coupling traditional methods and new tecnhology contributions to landslide risk assessment in the Arno river basin In Landslides: Evaluation and Stabilization. Taylor \& Francis Group, Rio de Janeiro: 151-156, 2004.

AUGUSTO FILHO, O.; MAGALHÃES, F. S. Identification of slope instability hazard areas in the Achienta-Imigrantes Highway System, located in the Serra do Mar mountain range, São Paulo state, Brazil. In: Landslides: Evaluation and Stabilization. Taylor \& Francis Group, Rio de Janeiro: 273-279, 2004.

AVANZI, G. D., GIANNECCHINI, R.; PUCCINELLI, A. The Influence of the geological and geomorphological settings on shallow landslides. An example in a temperature climate environment: the june 19, 1996 event in northwestern Tuscany (Italy). Engineering Geology 73: 215-228, 2004.

BROLLO, M. J.; SANTORO, J.; PENTEADO, D. R.; FERNANDES DA SILVA, P. C.; RIBEIRO, R. R. Itaóca (SP): Histórico de acidentes e desastres relacionados a perigos geológicos. $\mathbf{1 4}^{\circ}$ Simpósio de Geologia do Sudeste. Campos do Jordão - SP: 1-5. 2015.

BRASIL. Diário Oficial do Poder Executivo. São Paulo, 29 de janeiro de 2014. Seção I. p. 2-3

CARRARA, A., M. CARDINALI, F. GUZZETTI e P. REICHENBACH. Gis-Based techniques for mapping landslide hazard. 1995. http://deis158.deis.unib.it.

DIETRICH, W. E., R. R. D. ASUA, J. C. B. ORR e M. TRSO. A validation study of the shallow slope stability model, SHALSTAB, in the forest lands of Northern California. Stillwater Ecosystem, Watershaded \& Riverine Sciences, Berkeley. 1998.

FALEIROS, F. M.; MORAIS, S. M.; COSTA, V. S. Geologia e recursos minerais da Folha Apiaí SG.22-X-B-V, Estados de São Paulo e Paraná, Escala 1:100.000 - São Paulo: CPRM:.1-107. 2012. 
GRAMANI, M. F.; ARDUIN, D. H. Morfologia da drenagem dos depósitos de debris flow em Itaóca, São Paulo. $15^{\circ}$ Congresso Brasileiro de Geologia de Engenharia e Ambiental. In: Congresso Brasileiro de Geologia de Engenharia e Ambiental, Bento Gonçalves. Anais do $15^{\circ}$ Congresso Brasileiro de Geologia de Engenharia.São Paulo: ABGE, Cd-Rom, p.10. 2015.

LIN, C. C.; GRAMANI, M. F.; CAMPOS, A. B. Levantamento das Cicatrizes de Deslizamentos na Bacia do Rio Gurutuba (SP) e Correlações com Parâmetros Físicos. XVIII Congresso Brasileiro de Mecânica dos Solos e Engenharia Geotécnica - COBRAMSEG - 19-22 de Outubro, Belo Horizonte, Minas Gerais, Brasil. - .2016.

LOPES, E. S. S. Modelagem Espacial Dinâmica em Sistema de Informação Geográfica: Uma Aplicação ao Estudo de Movimentos de Massa em Uma Região da Serra do Mar Paulista. Tese (Doutorado). Universidade Estadual Paulista, Rio Claro, 314p. 2006.

MELLO, I.S.C.; BETTENCOURT, J.S. 1998. Geologia e Gênese das Mineralizações associadas ao Maciço Itaóca, Vale do Ribeira, SP e PR. Revista Brasileira de Geociências 28(3):269-284, 1998.

NERY, T. D. Dinâmica das corridas de detritos no Litoral Norte de São Paulo. Tese (Doutorado em Geografia Física) - Faculdade de Filosofia, Letras e Ciências Humanas, Universidade de São Paulo, São Paulo: 77-135. 2016.

NERY, T. D. 2011. Avaliação da suscetibilidade a escorregamentos translacionais rasos na bacia da Ultrafértil, Serra do Mar (SP). Dissertação (Mestrado em Geografia Física). Faculdade de Filosofia, Letras e Ciências Humanas, Universidade de São Paulo, São Paulo: 73-75 2011.

ROSS, J. L. S.; MOROZ, I. C. Mapa Geomorfológico do Estado de São Paulo. Laboratório de Geomorfologia. São Paulo: Departamento de Geografia - FFLCH - USP/Laboratório de Cartografia Geotécnica - Geologia Aplicada - IPT/FAPESP (Fundação do Amparo à Pesquisa do Estado de São Paulo). (Mapas e Relatórios). 1997.

SALCIARINI, D., GODT, J. W., SAVAGE, W. Z.; CONVERSINI, P.; BAUM, R. L.; MICHAEL, J. A. Modeling regional initiation of rainfall-induced shallow landslides in the eastern Umbria Regional of Central Italy. Landslides 3: 181-194. 2006.

SELBY, M. J. Hillslope: materials and process. Oxford, England: Oxford University Press: 117-151. 1993.

VAN WESTEN, C. J. Geo-information tools for landslide risk assessment: an overview of recent development. In: Landslides: Evaluation and Stabilization. Taylor \& Francis Group, Rio de Janeiro: 3953. 2004.

VARNES, D.J. Slope movement types and processes. In S. KRIZEK (ed) Slope movement types and processes, Washington, pp. 11-33. 1978.

VIEIRA, B. C. Previsão de escorregamentos translacionais rasos na Serra do Mar (SP) a partir de modelos matemáticos em bases físicas. Rio de Janeiro. Tese (Doutorado em Geografia). Programa de PósGraduação em Geografia, Universidade Federal do Rio de Janeiro: 97-103 2007.

VIEIRA, B. C.; RAMOS, H. Aplicação do modelo SHALSTAB para mapeamento da suscetibilidade a escorregamento rasos em Caraguatatuba, Serra do Mar (SP). Revista do Departamento de Geografia USP, Volume 29 (2015), 161 -174. 2015.

WU, W.; SIDLE. R. C. A distributed slope stability model for steep forested basins. Water Resources Research 31: 2097-2110. 1995. 